\title{
IMPLEMENTASI FUZZY INFERENCE SYSTEM TSUKAMOTO UNTUK PENENTUAN TOPIK TUGAS AHIR
}

\author{
Danang Mahendra \\ Fakultas Sains dan Teknlogi, Program Studi Sistem Informasi \\ Universitas Islam Nahdlatul Ulama Jepara \\ Email: danang@unisnu.ac.id \\ Noor Azizah \\ Fakultas Sains dan Teknlogi, Program Studi Sistem Informasi \\ Universitas Islam Nahdlatul Ulama Jepara \\ Email: azizah@unisnu.ac.id
}

\begin{abstract}
ABSTRAK
Pemilihan topik tugas akhir sangat penting dikarenakan akan berpengaruh pada kelulusan mahasiswa. Pemilihan topik tugas akhir akan disesuaikan dengan kompetensi mahasiswa, tujuannya agar mahasiswa dapat mengerjakan tugas akhir dengan tepat waktu dan lulus ujian tugas akhir. Salah satu pertimbangan untuk pemilihan menentukan topik tugas akhir mahasiswa adalah keterhubungan antara topik tugas akhir dengan nilai matakuliah dan sertifikasi yang diikuti mahasiswa. Belum adanya pemetaan topik tugas akhir yang tepat yang sesuai dengan kompetensi mahasiswa menyebabkan perlunya penggunaan suatu metode komputasi untuk memetakan mahasiswa dalam penentuan topik tugas akhir. Metode Fuzzy Inference System Tsukamoto merupakan salah satu bagian dari model heuristic yang digunakan untuk menyelesaikan masalah didalam sistem pendukung keputusan. Pada penelitian ini akan digunakan metode Fuzzy Inference System Tsukamoto untuk menentukan topik tugas ahir berdasakan nilai per topik tugas ahir dan sertifikasi mahasiswa. Hasil Pengujian yang telah dilakukan pada 172 sampel mahasiswa, menunjukkan bahwa penerapan Fuzzy Inference System Tsukamoto pada penentuan topik tugas akhir memiliki tingkat akurasi sebesar $88,39 \%$.
\end{abstract}

Kata kunci: penetuan topik tugas akhir, fuzzy inference system tsukamoto.

\begin{abstract}
Selection of final project topic is very important because it will affect the graduation of students. Selection of final project topics will be adapted to the competencies of students, the goal that students be able to finish the task on time and pass the final exam. One of the considerations for determining the selection of final project topic is connection between final assignment topics with course grades and student certification followed. The absence of mapping the exact final project topic that suits students led to the need for competence in the use of a computational method to map the student in determining the final topic. Tsukamoto Fuzzy Infrence System is one part of the heuristic models are used to solve problems in a decision support system. This research will be used Tsukamoto Fuzzy Inference System to determine the final project topic score per subject and student certification. Results Testing has been done on a sample of 172 college students, showed that the application of the Fuzzy Inference System Tsukamoto on the final project topic has an accuracy rate of $88.39 \%$.
\end{abstract}

Keywords: determination of final project topics, tsukamoto fuzzy inference system

\section{PENDAHULUAN}

Pengetahuan untuk pemilihan peminatan belajar sesungguhnya ada pada penasehat akademik mahasiswa. Akan tetapi pengetahuan ini tidak diketahui mahasiswa dengan baik. Akibatnya ada kemungkinan mahasiswa tidak memilih peminatannya dengan baik. Sama halnya dengan peminatan konsentrasi mata kuliah, penentuan pemilihan topik tugas akhir (TA) sebenarnya ada pada koordinator TA yang dapat dilihat dari nilai kompetensi setiap mahasiswa. Tetapi kondisi yang ada, koordinator TA belum mempunyai pemetaan tugas akhir berdasarkan kompetensi mahasiswa.

Pemilihan topik tugas ahir yang ada saat ini biasanya mahasiswa terkadang mengikuti pilihan yang sama dengan temannya, dimana jika temannya memilih topik A, maka dia juga akan memilih peminatan A dengan alasan, supaya mudah untuk belajar bersama, dan tanpa berfikir panjang bahwa pemilihan topik adalah menjadi hal yang sangat penting, karena dari pemilihan peminatan inilah nantinya mahasiswa akan 
mempertanggung jawabkan TA mereka, jika mahasiswa tidak dapat menjelaskan TA yang diambil dengan baik maka mahasiswa tersebut dapat dinyatakan tidak lulus. Pada pemilihan topik tugas akhir banyak mahasiswa dalam menentukan topik bersifat musiman sehingga jika ada mahasiswa yang mengambil topik A maka mahasiswa lain akan mengambil topik A juga dengan tujuan dapat dengan mudah dalam menyelesaikan tugas akhir secara bersama-sama padahal setiap mahasiswa mempunyai tingkat pemahaman topik yang berbeda-beda yang akan berpengaruh pada penyelesaian tugas akhir dan tingkat kelulusan.

Peminatan berdasarkan variabel minat dan bakat mahasiswa. Dengan menambahkan korelasi hubungan antara mata kuliah dengan peminatan akhir berdasarkan variabel minat dan bakat mahasiswa. Hasil penelitian ini bahwa pemilihan peminatan tugas akhir mahasiswa sangat menentukan hasil tugas akhir mahasiswa, dengan adanya FCM dapat membantu keakurasian pemilihan peminatan tugas akhir mahasiswa agar mahasiswa dapat memilih peminatan sesuai dengan kemampuan mahasiswa. Dan kevalidanya mencapai $80 \%{ }^{1}$

Sistem Pendukung Keputusan (SPK) merupakan sebuah sistem yang menyediakan kemampuan dalam penyelesaian masalah dan komunikasi untuk permasalahan yang bersifat semiterstruktur. Model heuristic merupakan salah satu model yang cukup popular dalam penyelesaian masalah dan Fuzzy Inference System Tsukamoto (FIS T s u k m o t o ) merupakan salah satu bagian dari model heuristic tersebut ${ }^{2}$. Kelebihan FIS Tsukamoto, antara lain: 1) FIS Tsukamoto memodelkan perasaan atau intuisi dengan cara merubah nilai crisp menjadi nilai linguistik dengan fuzzification dan kemudian memasukkannya ke dalam rule yang dibuat berdasarkan knowledge. 2) FIS Tsukamoto cocok digunakan pada sebagian besar permasalahan yang terjadi di dunia nyata. Permasalahan di dunia nyata kebanyakan bukan biner dan bersifat non linier sehingga FIS Tsukamoto cocok digunakan karena menggunakan nilai linguistik yang tidak linier.

Oleh karena itu, dibutuhkan adanya sebuah sistem informasi untuk menentukan topik TA mahasiswa menggunakan metode Fuzzy Inference System Tsukamoto. Variabel yang akan digunakan adalah nilai mahasiswa yang sudah di kelompokkan sesuai dengan kompetensi keahlian dan dengan menambahkan variabel serftifikasi mahasiswa. Sehingga dapat memperoleh nilai rekomendasi mahasiswa pertopik tugas akhir yang sesuai dengan kompetensi mahasiswa. Dan bisa mempermudah tugas koordinator TA dalam memberi rekomendasi pemilihan topik tugas akhir kepada mahasiswa.

\section{METODOLOGI PENELITIAN}

\subsection{Pengumpulan Data}

a. Jenis Data

Data yang digunakan dalam penelitian ini berupa data primer dan data sekunder:

1) Data Primer: berupa data tentang mekanisme pelaksanaan pemilihan topik tugas akhir yang dilaksanakan di UNSIQ, yang diperoleh dengan wawancara.

2) Data Sekunder: Merupakan data yang diperoleh secara tidak langsung, misalnya dari dokumentasi, literatur, buku, jurnal, dan informasi lainnya yang ada hubungannya dengan masalah yang diteliti. Jenis data yang digunakan dalam penelitian ini adalah data Sekunder yang diperoleh penulis secara langsung dari UNSIQ.

b. Sampel

Dalam pengambilan sampel, menggunakan teknik sampling Probability sampling. Probability sampling yaitu pengambilan sampel yang memberikan peluang yang sama bagi setiap unsur (anggota) populasi untuk dipilih menjadi anggota sampel.

Data populasi yang ada adalah 346 mahasiswa dan berdasarkan tabel penentuan populasi yang dikembangkan oleh Isaac dan Michael dengan tingkat kesalahan 5\% maka sampel yang diperlukan dalam penelitian adalah 172 mahasiswa.

Tabel 1. Sampel data

\begin{tabular}{clcc}
\hline No & Topik $\boldsymbol{T A}$ & Populasi & Sampel \\
\hline 1 & Pemrograman Visual & 155 & 77 \\
2 & Jaringan Komputer & 12 & 6 \\
3 & Pemrograman Web & 66 & 33 \\
4 & Sistem Informasi & 74 & 37 \\
5 & Pemrograman Multimedia & 39 & 19 \\
& Jumlah & & 172 \\
\hline
\end{tabular}




\subsection{Kerangka Pemikiran}

Berikut adalah kerangka pemikiran dari implementasi Metode Fuzzy Inference System (FIS) Tsukamoto yang dirancang oleh peneliti.

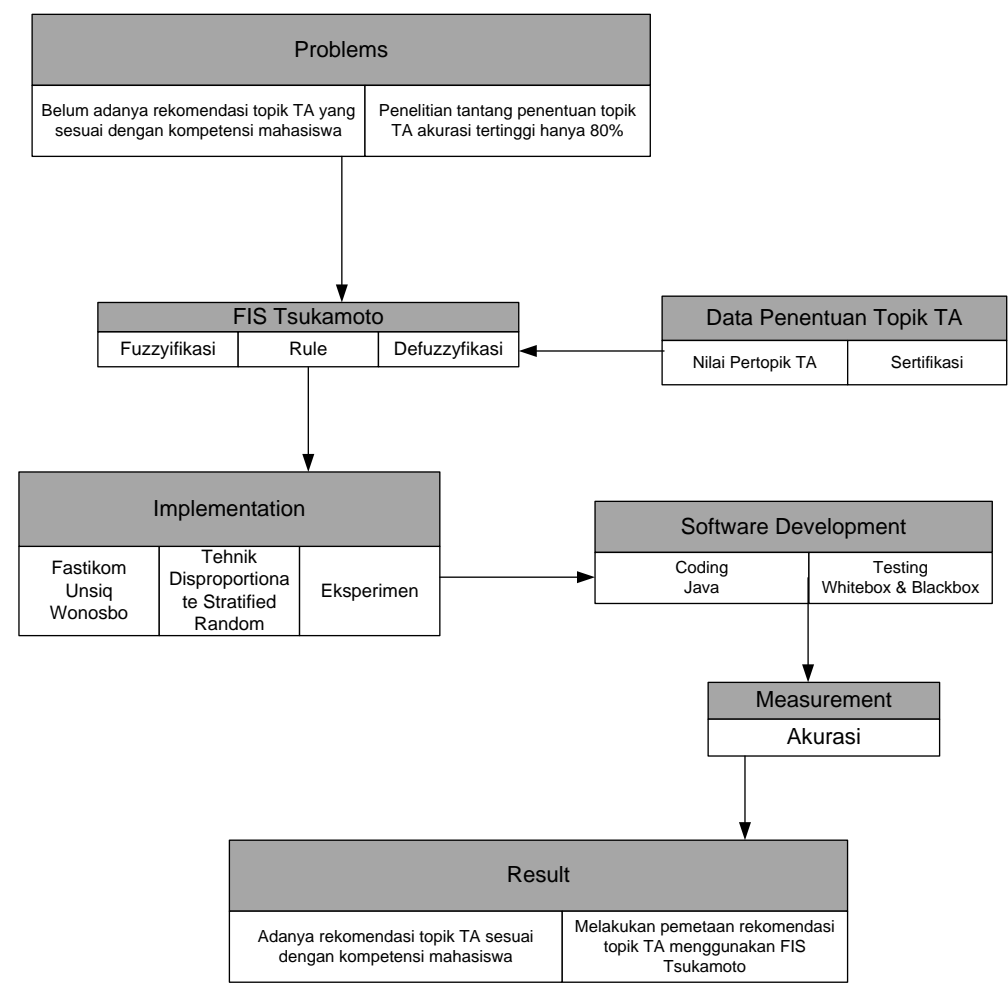

Gambar 1. Kerangka Pemikiran Penelitian

Koordinator TA UNSIQ Wonosobo kesulitan dalam memberikan rekomendasi penentuan topik TA kepada mahasiswa. Oleh karena itu diperlukan suatu teknik yang dapat melakukan pengelompokkan data secara cepat, mudah dan akurat. FIS Tsukamoto adalah salah satu metode yang bisa digunakan dalam menyelesaikan masalah di dalam SPK. Sehingga FIS Tsukamoto akan digunakan dalam pemberian SPK pada rekomendasi penentuan topik TA.

Data yang dipergunakan adalah data nilai mahasiswa pertopik matakuliah dan sertifikasi mahasiswa yang ada di UNSIQ Wonosobo. Data tersebut berjumlah 346 record. Sebelum diolah dengan menggunakan FIS Tsukamoto, data tersebut dilakukan preprocessing terlebih dahulu yaitu mencari nilai rata-rata pertopik tugas akhir. Dengan cara menginputkan semua nilai matakuliah yang mempunyai koneksitas dengan topik TA. Setelah di dapat nilai rata-rata pertopik TA maka akan dilakukan pembentukan fungsi keanggotaan variabel nilai pertopik TA dan variabel sertifikasi, lalu akan di bentuk rule aturan pertopik TA yang menghasilkan nilai output hasil dari tiap-tiap rule diberikan secara tegas (crisp) berdasarkan $\alpha$-predikat (fire strength). Hasil akhirnya diperoleh dengan menggunakan rata-rata terbobot (defuzzyifikasi).

Hasil akurasi diperoleh dari membandingkan nilai TA mahasiswa dari topik TA dan nilai besarnya nilai rata-rata terbobot dari topik TA. Selain itu, untuk mengetahui seberapa besar tingkat akurasi penggunaan FIS Tsukamoto dalam penentuan topik TA.

\section{HASIL PENELITIAN DAN PEMBAHASAN}

\subsection{Penerapan FIS Tsukamoto}

\subsubsection{Penentuan Fungsi Keanggotaan}

Dalam penelitian ini, setiap variabel fuzzy menggunakan fungsi keanggotaan linier naik, linier turun, dan segitiga sebagai pendekatan untuk memperoleh derajat keanggotaan suatu nilai dalam suatu himpunan fuzzy. Bentuk kurva berikut ini adalah kurva default dari beberapa faktor yang mempengarui penentuan topik TA beserta himpunan-himpunannya. Variabel ini terdiri dari 3 himpunan fuzzy yaitu : 
rendah, sedang, dan tinggi. Himpunan rendah dengan bobot nilai $[0,00-2,75]$, himpunan sedang dengan bobot nilai $[2,00-3,50]$, dan himpunan tinggi dengan bobot nilai $[2,75-4,00]$. Berikut gambar fungsi keanggotaannya :

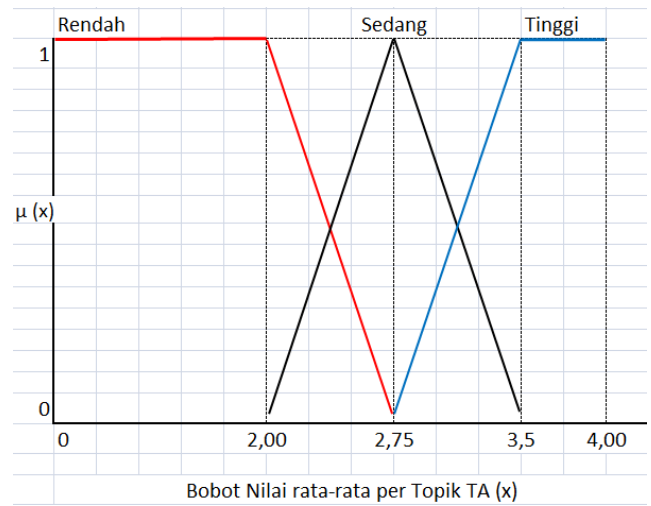

\section{Gambar 2. Fungsi Keanggotaan Pada Variabel Nilai Per Topik TA}

\subsubsection{Perancangan Rule}

Kumpulan aturan merupakan salah satu ciri dan syarat yang harus ada pada FIS Tsukamoto. Aturan fuzzy yang dibuat, menggunakan variable input berupa nilai rata-rata per topik tugas akhir dan sertifikasi, dan variable output yang berupa nilai rekomendasi konsentrasi per topik TA.

Pembentukan Aturan Topik TA Jaringan Komputer :

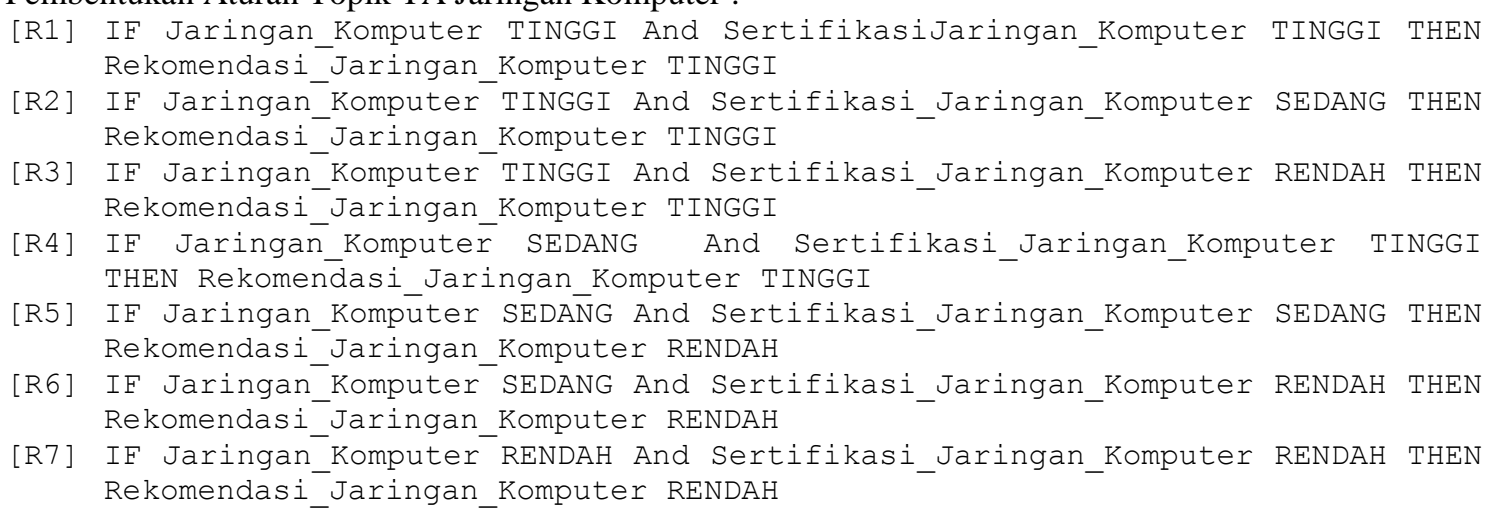

\subsubsection{Defuzzyfikasi}

Setelah itu hasil akhir diperoleh dengan menggunakan rata-rata terbobot. Defuzzifikasi Topik TA Jaringan Komputer adalah sebagai berikut

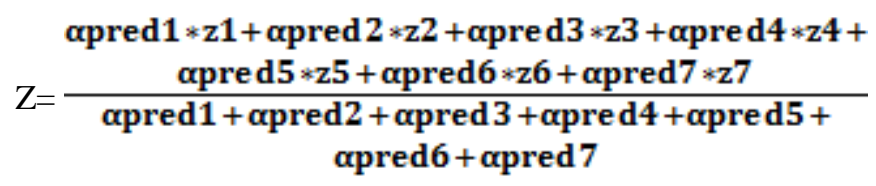

\subsubsection{Analisis Hasil}

Dalam penelitian ini, peneliti akan mengambil satu sampel data nilai mahasiswa dan sertifikasi mahasiswa yaitu mahasiswa dengan NIM 8004086. 
Tabel 3. Tabel nilai mahasiswa dengan NIM 8004086

\begin{tabular}{rlcrlc}
\hline No & Makul & Nilai & No & Makul & Nilai \\
\hline 1 & Pemograman I & A & 11 & Pemograman III & A \\
2 & PHP & C & 12 & Logika informatika & A \\
3 & Teknik pengolahan citra & B & 13 & Keamanan jarkom & A \\
4 & Jaringan Komputer & B & 14 & SIM & A \\
5 & APSI & A & 15 & Kewirausahaan & C \\
6 & Pemograman II & B & 16 & Tehnik Pemograman & B \\
7 & E-Commerce & A & 17 & Sistem Operasi & A \\
8 & Animasi komputer & A & 18 & Pengenalan UML & A \\
9 & Komunikasi Data & A & 19 & Struktur Data & B \\
10 & PBD & B & & & \\
\hline
\end{tabular}

a. Penentuan Fungsi Keanggotaan (fuzzyfikasi) untuk NR1/Jaringan Komputer

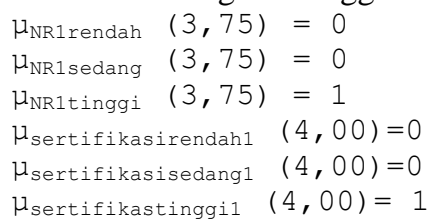

b. Menentukan Rule dan Defuzzifikasi Jaringan Komputer

[R1] IF Jaringan Komputer TINGGI And SertifikasiJaringan Komputer TINGGI THEN Rekomendasi_Jaringan_Komputer TINGGI

Pada metode FIS Tsukamoto, untuk menentukan output crisp, digunakan deffuzyfikasi rata-rata terpusat, yaitu:

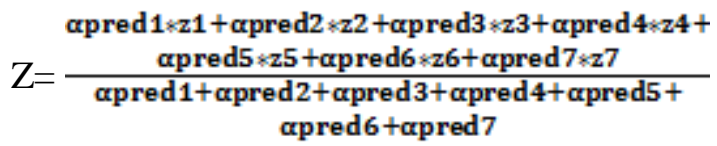


$\mathrm{Z}=$

$1+0+0+0+0+0+0$

$\mathrm{Z}=4$

Jadi rekomendasi penentuan topik jaringan komputer adalah rekomendasi tinggi dengan nilai $\mathrm{Z}=$ 4,00

Dari perhitungan menggunakan FIS Tsukamoto NIM 8004086 mempunyai nilai rekomendasi :

a) Jaringan Komputer 4,00 - Rekomendasi Tinggi

b) Sistem Informasi 3,12-Rekomendasi Tinggi

c) Pemrograman Multimedia 3,12 - Rekomendasi Tinggi

d) Pemrograman Web 3,12 - Rekomendasi Tinggi

e) Pemrograman Visual 4,00 - Rekomendasi Tinggi

\subsection{Hasil Pengujian}

Berdasarkan hasil pengujian akurasi FIS Tsukamoto dari hasil penelitian yang diperoleh data sampel, didapatkan tingkat akurasi sebesar $88,39 \%$. Berikut adalah hasil yang ditampilkan pada grafik :

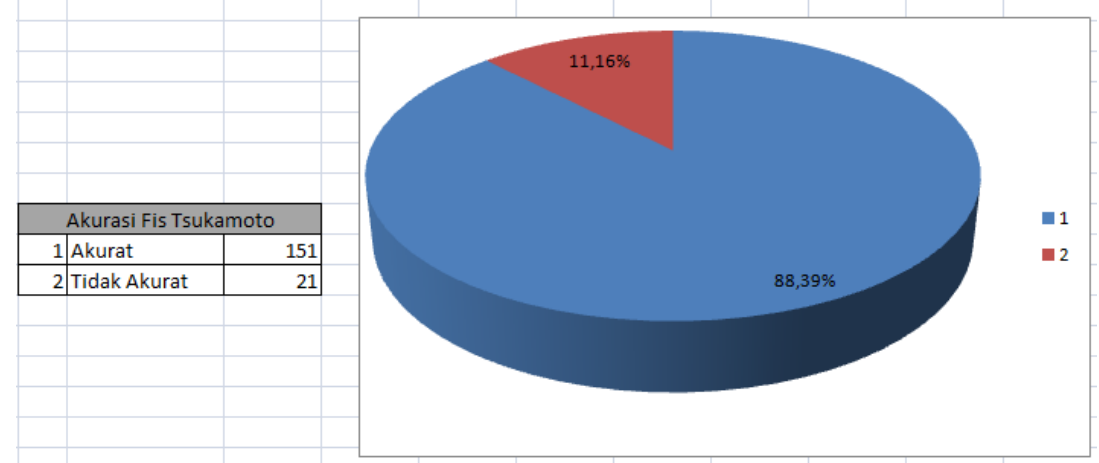

Gambar 3. Grafik Hasil Akurasi Menggunakan FIS Tsukamoto

\subsection{Impementasi Program}

Untuk menentukan besarnya rekomendasi penentuan topik TA, maka nilai semua matakuliah dan sertifikasi yang relevan harus diberikan sebagai data input. Sistem memfasilitasi pamasukan data nilai setiap matakuliah dan sertifikasi mahasiswa. Berikut adalah tampilan user interface dari aplikasi penentuan topik TA :

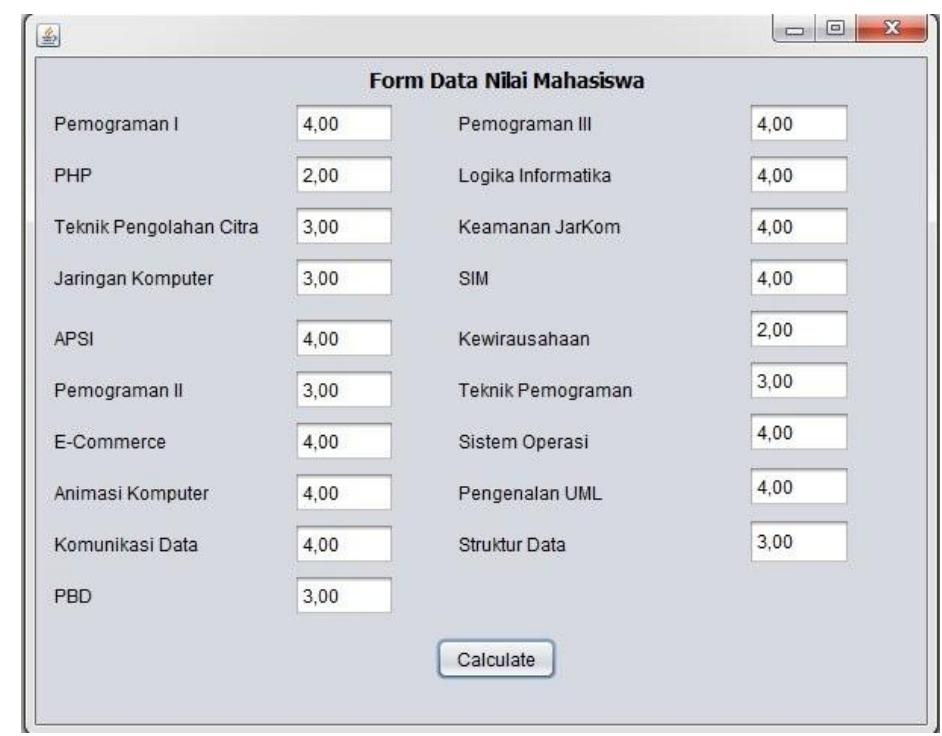

Gambar 3. Form Data Nilai

Form ini digunakan untuk melakukan input data nilai yang berisi semua matakuliah yang berkorelasi dengan topik TA. Administrator menginput semua nilai, setelah semua kolom nilai 
terisi tekan tombol calculate untuk mendapatkan nilai rata-rata pertopik TA. Selanjutnya adalah menampilkan form data sertifikasi yang berisi tentang nilai rata-rata matakuliah per topik TA. Berkut adalah gambar halaman form sertifikasi dan form laporan hasil peminatan TA :

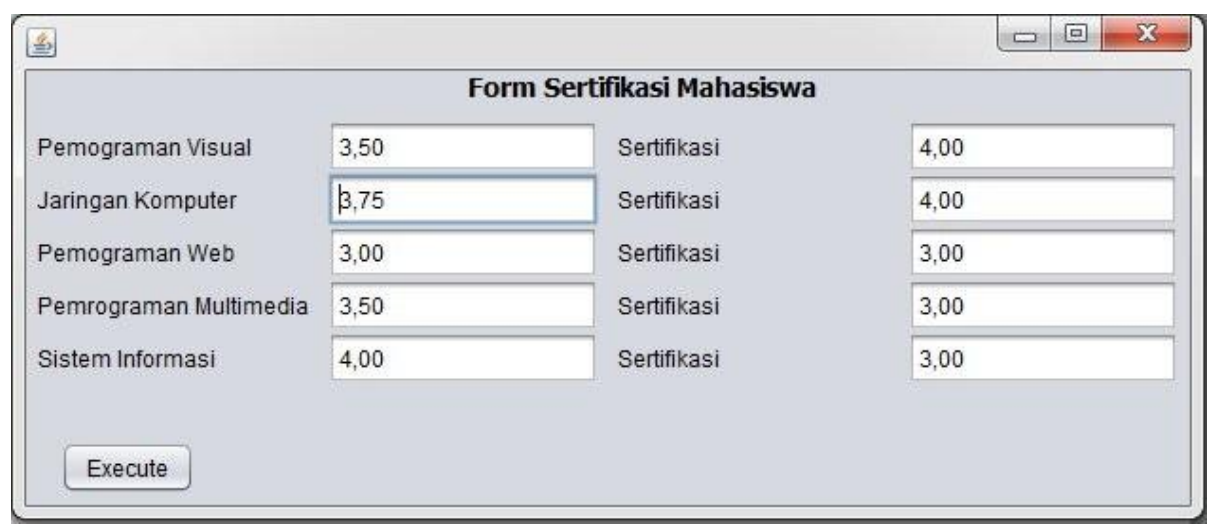

Gambar 4. Form Data Sertifikasi

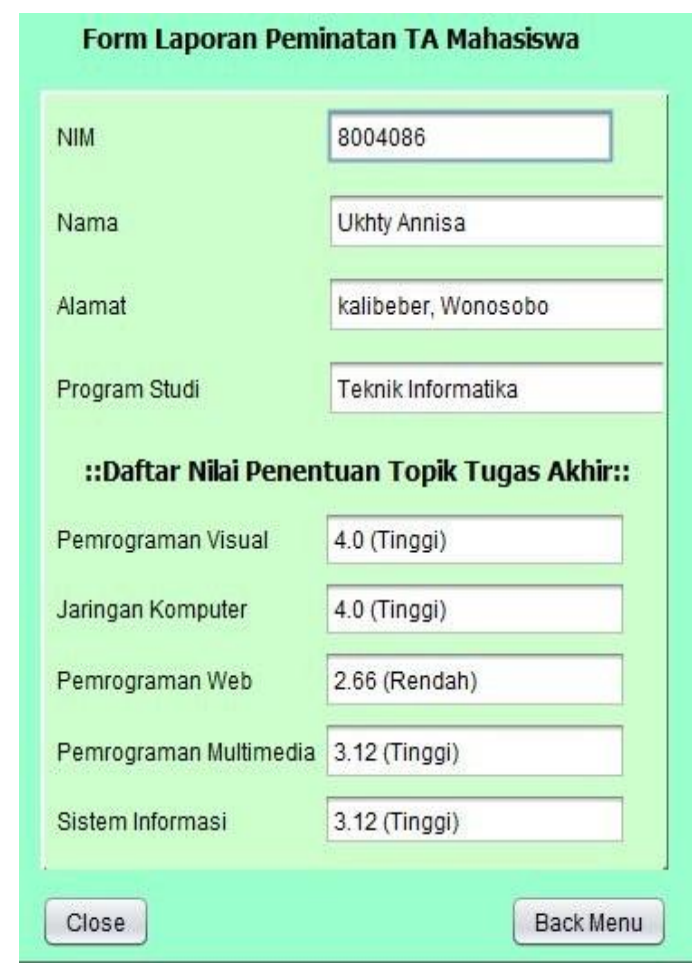

Gambar 5. Form Laporan Peminatan TA

\section{KESIMPULAN}

Hasil dari penelitian ini dapat disimpulkan antara lain :

a) Metode FIS Tsukamoto dapat digunakan untuk rekomendasi penentuan topik tugas ahir

b) Dari hasil pengujian yang dilakukan pada 172 sampel data mahasiswa Universitas Sains Al-Quran Wonosobo, metode FIS Tsukamoto memiliki tingkat akurasi yang lebih tinggi (yaitu 83,39\%), jika dibandingkan dengan metode-metode lain yang digunakan untuk rekomendasi penentuan topik TA yang selama ini dilakukan yaitu Metode Fuzzy Tsukamoto 80\%.

\section{DAFTAR PUSTAKA}

[1] Sumanto. 2010. Penerapan Fuzzy C-Means (Fcm) Dalam Pemilihan Peminatan Tugas Akhir Mahasiswa. STMIK Nusamandiri. 
[2] Rakhman, A. Z., et al. 2012. Fuzzy Inference System Dengan Metode Tsukamoto Sebagai Pemberi Saran Pemilihan Konsentrasi. SNATI vol. 2012, 15-16.

[3] Bahar. 2011. Penentuan Jurusan Sekolah Menengah Atas Dengan Algoritma Fuzzy C-Means. UDNUS.

[4] Jang, J.S.R., Sun, C.T., dan Mizutani, E., 1997, Neuro-Fuzzy And Soft Computing, A Computational Approach to Learning and Machine Intelligence, Prentice-Hall International, Inc, USA

[5] Kusumadewi, Sri, et al. (2006). Fuzzy Multi-Attribute Decision Making (Fuzzy MADM). Yogyakarta : Graha Ilmu. 